\title{
Advances in dissolved organic matter in waters based on
}

\section{three-dimensional fluorescence spectrometry}

\author{
Lizhen Liu ${ }^{1, a *}$, Yongming $\mathrm{Wu}^{1}$, Mi Deng ${ }^{2}$, Hailin You ${ }^{1}$, Wenqing $\mathrm{Tu}^{1}$ \\ ${ }^{1}$ Poyang Lake Research Center, Jiang Xi Academy Science, Nanchang 330096, China \\ ${ }^{2}$ Nanchang University, Nanchang 330031, China \\ aemail: woliulizhen2007@126.com
}

${ }^{*}$ Corresponding author: Liu Lizhen (1987-), female, Wannian county in Jiangxi province, Research assistant, PHD, Major in water environmental ecology and engineering, Email: woliulizhen2007@126.com.

Keywords: Dissolved organic matter; Three dimensional excitation-emission fluorescence; Application

Abstract: Dissolved organic matter (DOM) is a kind of dissolved materials containing humic-like, protein-like and carbohydrates, which distributed widely in various kinds of water body. Due to the complex components, it is hard to analyze fully specific organic fraction. Due to three dimensional excitation-emission fluorescence (3DEEM) technique with the merits of high sensitivity, high selectivity, simple operation, and non-destructive and less sample, it has become one reliable method to study DOM. This study gave a brief introduction for 3DEEM technique, and reviewed from the characterization of DOM and the relationship between DOM and heavy metals. Additionally, we also summarized the application of 3DEEM in DOM from natural water environment and wastewater treatment to provide the theoretical basis and technical support for geochemical cycling of pollutants and water environmental protection and control.

\section{Introduction}

Dissolved organic matter (DOM) is a kind of important, very active materials in terrestrial and aquatic ecosystems, which has a direct influence on nutrients (carbon, nitrogen, and phosphorus) cycling, the toxicity of pollutants and transformation characteristics, and even on human health ${ }^{[1-3]}$. However, It has been a long time for lacking suitable method to analyze specific components, and to acquire detailed information because of complex components in DOM. Recently, 3DEEM with the simple and fast, highly sensitive, very selective and non-destructive merits has been developed ${ }^{[4}$, ${ }^{5]}$, and was regarded as the simplest, and the most effective technique to study the components, concentrations and sources of DOM. As yet, this technique has been applied in many fields such as natural water bodies (lakes, rivers, and oceans), soil and water treatments and so on.

The principle of fluorescence spectrum is that molecules absorbed ultraviolet and visible spectrum and then emitted after the transition. These molecules in excited state would return to the ground state, which were often associated with a certain wavelength of light (fluorescence). The fluorescence spectrum technique was a quantitative and qualitative method to determine the fluorescent intensity and wavelength. Three dimensional excitation-emission fluorescence (3DEEM) was a new fluorescence analysis method in recent years, which was based on excitation-emission 
matrix (EEM) from the different excitation wavelength (Ex) scanning on emission (Em) spectrum. 3DEEM could simultaneously acquire and characterize different fluorescence information to provide unique "fingerprint" tracer technique, and could reveal the relative concentration and distribution change.

\section{Functions of 3DEEM}

\section{Characterizing the components and concentrations of DOM}

The peak location of 3DEEM could characterize DOM components. The fluorescent intensities could represent DOM concentration. Generally, the components of DOM characterized by 3 DEEM were divided into two classes (protein-like and humic-like matters) ${ }^{[6]}$. The common peaks were shown in Table 1.

Additionally, there were some researchers to further explore the information from 3DEEM and extended their application. For example, Liu et al. ${ }^{[7]}$ found the peak wavelength of the pollutants (Hydroquinone: Ex/Em=298 nm/330 nm; biphenyl compounds: Ex/Em=294 nm/315 nm), and built the relationship between concentrations and fluorescence intensities.

Many kinds of fluorophores were involved in the 3DEEM spectra, which could stack with each other to cause inaccurate identification. To solve this problem, Stedmon et al. ${ }^{[8]}$ (2003) used parallel factor analysis (PARAFAC) to break the stacking fluorophores into independent fluorescent components. This method was better than the traditional "peak peaking" method, and could help to reveal more information from EEM.

Table 1 Spectral characteristics of excitation and emis sion maxima

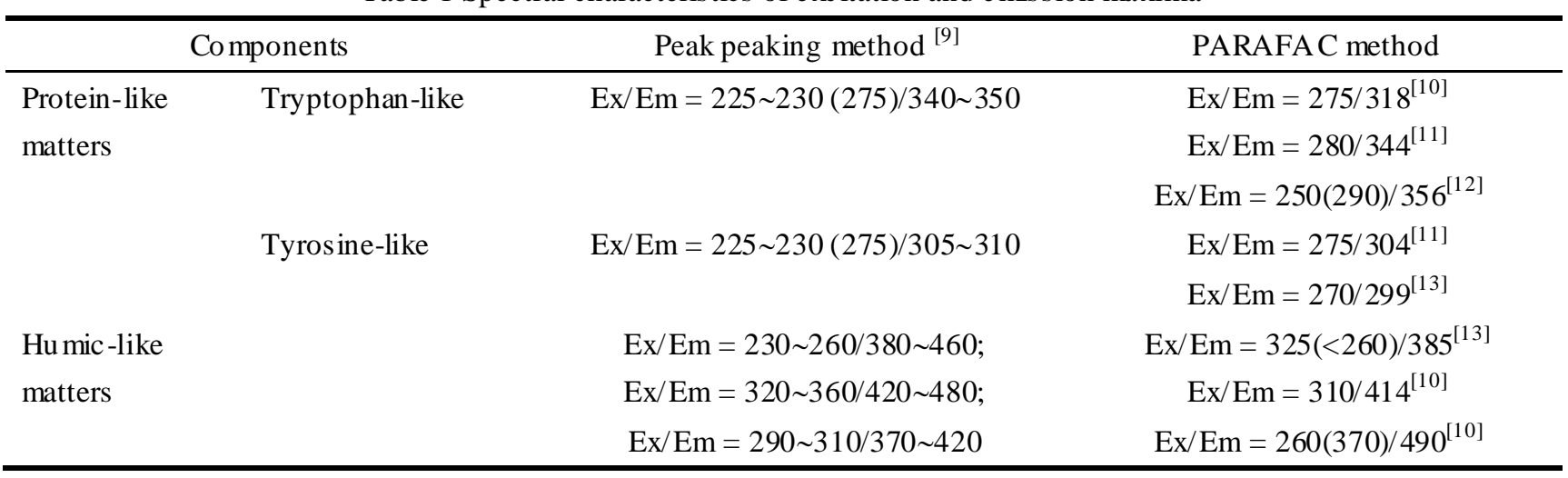

\section{Tracing and resolving the sources of DOM}

Generally, protein-like materials (tryptophan-like and tyrosine-like) were from biological activity, and humic-like materials were from terrestrial or marine environments. So monitoring these fluorescent materials could reach the purpose of tracing DOM. Due to the protein-like materials in polluted waters were always significantly related to organic pollution index such as biochemical oxygen demand (BOD) and chemical oxygen demand (COD), these fluorescent materials could be monitored the polluted status in waters ${ }^{[14]}$. Henderson et al ${ }^{[15]}$ summarized that 3DEEM technique could be used as a useful monitoring tool, and pointed that the ratio of peak values of humic-like to protein-like materials was used to identify the contamination status.

The sources of DOM could be estimated from three fluorescence indices, that is, fluorescent index $\left(\mathrm{FI}_{370}\right)$, the humification index (HIX), and biological index (BIX). The fluorescent index $\left(\mathrm{FI}_{370}\right)$ was defined as the ratio of fluorescence intensity at the emission wavelength $450 \mathrm{~nm}$ to that at $500 \mathrm{~nm}$ at excitation wavelength $370 \mathrm{~nm}$. This index could distinguish the external source input and/ or autogenic source ${ }^{[4]}$. McKnight et al. ${ }^{[16]}$ (2001) indicated that, $\mathrm{FI}_{370}$ is about 1.4 for biological sources and about 1.9 for terrestrial sources. HIX is calculated by the ratio of average value between emission wavelengths 300 and $345 \mathrm{~nm}$ to that between 435 and $480 \mathrm{~nm}$ at excitation wavelength $254 \mathrm{~nm}^{[17]}$. When the degree of aromaticity of DOM increases, HIX increases. Huguet et al. ${ }^{[17]}$ pointed that when HIX index was less than 4, DOM was mainly from autochthonous biological 
activity, and the humification degree was relatively weak; when HIX index was high, DOM was mainly from terrestrial origin. BIX is the index of recent autochthonous contribution, indicating the presence of the autochthonous biological activity. BIX index is determined as the ratio of fluorescence intensity at $380 \mathrm{~nm}$, divided by that at $430 \mathrm{~nm}$, both excited at $310 \mathrm{~nm}$. High values of BIX $(>1)$ corresponded to a predominantly autochthonous origin, whereas low values indicated lower autochthonous DOM ${ }^{[17]}$. Overall, these indices for characterizing DOM source were shown in Table 2.

Table 2 Fluorescence indices for characterizing DOM source ${ }^{[4]}$

\begin{tabular}{lll}
\hline $\begin{array}{l}\text { Fluorescence } \\
\text { indices }\end{array}$ & Ranges & Characteristics \\
\hline $\mathrm{FI}_{370}$ & $<1.4$ & Terrestrial origin \\
& $1.4 \sim 1.9$ & Biological or terrestrial origin \\
& $>1.9$ & Biological origin \\
HIX & $<4$ & Biological or aquatic bacterial orig in \\
& $4 \sim 6$ & Weak humic character and recent autochthonous origin \\
& $6 \sim 10$ & Strong humic character and weak recent autochthonous origin \\
& $>16$ & Strong humic character and high terrigeneous contribution \\
BIX & $0.6 \sim 0.7$ & Weak autochthonous origin \\
& $0.7 \sim 0.8$ & Intermediate autochthonous origin \\
& $0.8 \sim 1$ & Strong autochthonous origin \\
& $>1$ & Biological or aquatic bacterial orig in \\
\hline
\end{tabular}

Through these indices, Xiao et al. ${ }^{[18]}$ identified that DOM in South Sea in China mainly derived from marine autochthonous biological activity. Zhang et al. ${ }^{[4]}$ concluded that the DOM in 38 lakes of Yungui Plateau in different eutrophic status was simultaneously affected by autochthonous and external sources.

\section{Studying the relationship between DOM and heavy metals}

DOM contained carboxyl, amino and phenolic hydroxyl groups and so on, which could combine and carry a lot of metal ions and hydrophobic organic compounds, and further changed the transport and transformation of pollutants. Through studying the interaction between DOM and arsenic (As) and antimony (Sb), Zhang et al ${ }^{[19]}$ showed that stronger binding capacity of protein-like than humic-like component for As/Sb. Similar result also showed that the chelate ability for lead $(\mathrm{Pb}(\mathrm{II}))$ of protein-like was stronger than humic-like matters ${ }^{[20]}$. Fu et al. ${ }^{[21]}$ studied the interaction between DOM in rivers and mercury $(\mathrm{Hg}(\mathrm{II}))$ by $3 \mathrm{DEEM}$, and showed that the fluorescent matters including humic-like matters in DOM were strong organic ligands on $\mathrm{Hg}$ (II). Wu et al. ${ }^{[22]}$ further verified the rapid coupling function between DOM and $\mathrm{Hg}$. The $\mathrm{Hg}(\mathrm{II})-\mathrm{DOM}$ system could reach quasi-equilibrium status in $20 \mathrm{~s}$. Additionally, the fluorescent peak wavelength was red-shifted, indicating that the structure of DOM changed after interaction.

\section{Application in natural waters}

Characterizing DOM in natural waters by the 3DEEM technique was firstly applied in marine waters $^{[6]}$. Coble ${ }^{[6,9]}$ pointed that there were 5-6 fluorophores in seawater. Due to the lake was simultaneously affected by terrestrial input and biological activity, there were also many fluorescent peaks in lake waters. For example, DOM in Lake Taihu contained humic-like, tryptophan-like and tyrosine-like matters ${ }^{[23]}$. However, the components in ground waters were relatively simpler. Yao et al. ${ }^{[24]}$ showed that DOM in Karstic ground water was mainly composed of terrestrial humic-like matters, which was consist with Fu et al. ${ }^{[25]}$. Additionally, Liu et al. ${ }^{[26]}$ built the relationship 
between the fluorescent components of DOM in coastal ocean in China and eutrophication indexes, and showed that using 3DEEM technique to estimate the eutrophic status is rapid and feasible.

\section{Application in wastewater treatments}

Fluorescence spectroscopy as an effective monitoring tool has been applied to monitor water quality and pollution in rivers ${ }^{[27]}$, control wastewater treatment process ${ }^{[27-29]}$, determine specific organic contaminants in wastewaters ${ }^{[30]}$, monitor the recycled waters after wastewater treatments ${ }^{[15]}$ and characterize water quality in the wastewater treatment process ${ }^{[31]}$. Recently, COD and BOD as the organic matters indexes were used in wastewater treatment process. However, these assay procedures were complex, which spent a long time to determine, and further caused secondary pollution. So studying fluorescence spectroscopy of DOM in inflow and effluent in wastewater treatments was useful to identify the removal effects of organic matters in waters. Lv et al. ${ }^{[32]}$ measured the water quality during the treatment of feed water by 3DEEM technique, and showed that the visible humic-like matters were largely removed through the process (sedimentation tank-V-type filter-general filter), and the remove rate reached $70 \%$. Through using 3DEEM to explore the treatment status of rural eutrophic water by constructed wetlands, Deng et al. [33] showed that the peak intensities of tyrosine-like and tryptophan-like matters both decreased after treatment, and the peak intensities of humic-like matters increased. This suggested that organic matters became more humified after treatment. Additionally, Liu et al ${ }^{[34]}$ extended 3DEEM technique into reflect the cause of biofilm pollution and the capture efficiency of biofilm, and further showed that protein-like and humic-like matters were the main fluorescent signals to cause biofilm pollution. Besides, the intensities could characterize the capture efficiency of film.

\section{Conclusions}

3DEEM technique could rapidly measure DOM, and has the characteristics of high sensitivity, simple process, less and non-destructive sample, and tracing function and primarily identifying sources. As mentioned above, this technique has been widely applied in natural waters, water quality monitoring, water treatment engineering and so on. It should be noted that, 3DEEM only characterized the fluorescent matters in DOM. So according to the research purpose, other analysis techniques such as molecular determination, infrared spectroscopic analysis and nuclear magnetic resonance would be used together to characterize DOM.

\section{Acknowledgments}

This work was supported by the Youth Natural Scientific Foundation of Jiangxi Province (20151BAB213033), by the Doctoral Project of Jiangxi Academy of Science (2014-YYB-30; 2014-YYB-31(29)), and by the GSP Project from Special Fund of Collaborative Innovation in Jiangxi Academy of Sciences (2014-XTPH1-30; 2014-XTPH1-31(29)).

\section{References}

[1] Lehman R M, Mills A L. Field evidence for copper mobilization by dissolved organic matter [J]. Water Research, 1994, 28(12): 2487-2497.

[2] Kalbitz K, Wennrich R. Mobilization of heavy metals and arsenic in polluted wetland soils and its dependence on dissolved organic matter [J]. Science of the Total Environment, 1998, 209(1): 27-39.

[3] Fu P Q, Liu C Q, Wan Y X, et al. Review of the effects of humic substances on heavy metal behavior in aquatic environments [J]. Bulletin of Mineralogy, Petrology and Geochemistry, 2002, 21(4):277-281. 
[4] Zhang Y, Zhang E, Yin Y, et al. Characteristics and sources of chromophoric dissolved organic matter in lakes of the Yungui Plateau, China, differing in trophic state and altitude [J]. Limnology and Oceanography, 2010, 55(6): 2645-2659.

[5] Patra D, Mishra A. Recent developments in multi-component synchronous fluorescence scan analysis [J]. TrAC Trends in Analytical Chemistry, 2002, 21(12): 787-798.

[6] Coble P G, Green S A, Blough N V, et al. Characterization of dissolved organic matter in the Black Sea by fluorescence spectroscopy [J]. 1990.

[7] Liu X J. Study on the three-dimensional fluorescence characteristics of pollutants of surface drinking water source [D]. Hebei University of Science and Technology, 2012.

[8] Stedmon C A, Markager S, Bro R. Tracing dissolved organic matter in aquatic environments using a new approach to fluorescence spectroscopy [J]. Marine Chemistry, 2003, 82(3): 239-254.

[9] Coble P G. Characterization of marine and terrestrial DOM in seawater using excitation-emission matrix spectroscopy [J]. Marine Chemistry, 1996, 51(4): 325-346.

[10] Murphy K R, Stedmon C A, Waite T D, et al. Distinguishing between terrestrial and autochthonous organic matter sources in marine environments using fluorescence spectroscopy [J]. Marine Chemistry, 2008, 108(1): 40-58.

[11] Stedmon C A, Markager S. Resolving the variability in dissolved organic matter fluorescence in a temperate estuary and its catchment using PARAFAC analysis [J]. Limnology and Oceanography, 2005, 50(2): 686-697.

[12] Kowalczuk P, Durako M J, Young H, et al. Characterization of dissolved organic matter fluorescence in the South Atlantic Bight with use of PARAFAC model: Interannual variability [J]. Marine Chemistry, 2009, 113(3): 182-196.

[13] Yamashita Y, Jaffé R, Maie N, et al. Assessing the dynamics of dissolved organic matter $(\mathrm{DOM})$ in coastal environments by excitation emission matrix fluorescence and parallel factor analysis (EEM - PARAFAC) [J]. Limnology and Oceanography, 2008, 53(5): 1900-1908.

[14] Baker A. Fluorescence excitation-emission matrix characterization of some sewage-impacted rivers [J]. Environmental science \& technology, 2001, 35(5): 948-953.

[15] Henderson R, Baker A, Murphy K, et al. Fluorescence as a potential monitoring tool for recycled water systems: A review [J]. Water Research, 2009, 43(4): 863-881.

[16] Mcknight D M, Boyer E W, Westerhoff P K, et al. Spectrofluorometric characterization of dissolved organic matter for indication of precursor organic material and aromaticity [J]. Limnology and Oceanography, 2001, 46(1): 38-48.

[17] Huguet A, Vacher L, Relexans S, et al. Properties of fluorescent dis solved organic matter in the Gironde Estuary [J]. Organic Geochemistry, 2009, 40(6) : 706-719.

[18] Xiao R G, Chen W S, Chen G F, et al. Fluorescence excitation-emission matrix spectroscopy of chromophoric dissolved organic matter in the South China Sea [J]. Acta Scientiae Circumstantiae, 2014, 34(1):160-167.

[19]Zhang D. Characterization of dissolved organic matter (DOM) in the Yangtze Estuary and its interactions with As/Sb [D].. Beijing Normal University, 2013.

[20] Meng H T, Li G, Zhang J, et al. Complexation between lead and dissolved fluorescent organic matter from leachates [J]. Environmental Che mistry [J], 2015, 34(2): 327-332.

[21] Fu P Q, Liu C Q, Wu F C. Three-dimensional excitation emission matrix fluorescence spectroscopic characterization of the complexation between mercury (II) and dissolved organic matter [J]. Environmental Science, 2004, 25(6): 140-144. 
[22] Wu F, Cai Y, Evans D, et al. Complexation between Hg (II) and dissolved organic matter in stream waters: an application of fluorescence spectroscopy [J]. Biogeochemistry, 2004, 33(6): 1619-1625.

[23]Zhu P, Hua Z L, Li H M. PARAFAC method used for analysis of three-dimensional fluorescence spectra of DOM in Taihu Lake. [J]. Spectroscopy and Spectral Analysis, 2013, 33: 1619-1625.

[24] Yao X, Zhou S Z, Xia R Y, et al. Dissolved organic matter (DOM) dynamics in Karst Aquifer systems [J]. Environmental Science, 2014, 35(5): 1766-1772.

[25] Fu P Q, Liu C Q, Wu F C. Three-dimensional excitatioin emission matrix fluorescence spectroscopic characterizatioin of dissolved organic matter [J]. Spectroscopy and Spectral Analysis, 2006, 25(12): 2024-2028.

[26] Liu Y F, Su R G, Zhou Q Q, et al. Rapid modeling offshore eutrophication technique using optical parameters of CDOM [J]. Chinese Journal of Lasers, 2014, 41(12): 1-8.

[27] Hudson N, Baker A, Reynolds D. Fluorescence analysis of dissolved organic matter in natural, waste and polluted waters - a review [J]. River Research and Applications, 2007, 23(6): 631-649.

[28] Ahmad S, Reynolds D. Monitoring of water quality using fluorescence technique: prospect of on-line process control [J]. Water Research, 1999, 33(9): 2069-2074.

[29] Reynolds D, Ahmad S. Rapid and direct determination of wastewater BOD values using a fluorescence technique [J]. Water Research, 1997, 31(8): 2012-2018.

[30] Kuzniz T, Halot D, Mignani A, et al. Instrumentation for the monitoring of toxic pollutants in water resources by means of neural network analysis of absorption and fluorescence spectra [J]. Sensors and Actuators B: Chemical, 2007, 121(1): 231-237.

[31] Jin X, Jin P K, Kong Q, et al. Ozonation characteristics of DOM in secondary effluent based on fluorescence PARAFAC analysis [J]. China Environmental Science, 2015, 35(2): 427-433.

[32]Lv H G, Ouyang E M, Zhen Z H, et al. Three dimensional fluorescence spectroscopy for water quality determination in water treatment plant [J]. China Water \& Wastewater, 2005, 21(3): 91-93.

[33] Deng $\mathrm{H} \mathrm{H}$. A study on remediation of rural eutrophic water and mechanism by using constructed wetlands [D]. Tongji University, 2007.

[34]Liu Z, Dong B Z, Chen Y et al. Characterization of membrane foulants by using three demensional excitation and emission matrix fluorescence spectroscopy [J]. Environmental Chemistry, 2010, 29(

[35] 3): 496-501. 